\title{
Indexes derived from non-linear ESPVR for evaluation of ventricular performance
}

\author{
R. M. Shoucri \\ Department of Mathematics and Computer Science, \\ Royal Military College of Canada, Canada
}

\begin{abstract}
Indexes derived from the non-linear end-systolic pressure-volume relation (ESPVR) are introduced in a way to study the performance of the left ventricle of the heart. The study sheds some light on the problem of heart failure with normal or preserved ejection fraction (HFpEF). It is shown that the ejection fraction (EF) is one index of several indexes that can be derived from the ESPVR in order to assess the performance of the left ventricle. Pressures acting on the left ventricle (ordinates of the ESPVR) as well as areas under the ESPVR (units of energy) can be used in assessing the performance of the left ventricle.

Keywords: cardiac mechanics, mathematical physiology, pressure-volume relation in the ventricles, peak isovolumic pressure, active force of the myocardium, ventricular elastance, heart failure with preserved ejection fraction.
\end{abstract}

\section{Introduction}

In previous studies the author has introduced a new relation that can be used to calculate the non-linear end-systolic pressure-volume relation (ESPVR) in the left ventricle. This relation is based on a mathematical formalism in which the active force of the myocardium is introduced in the mathematical formalism describing the pressure-volume relation (PVR) in the left ventricle [1-4]. In a quasi-static approximation (inertia forces and viscous forces neglected) the active force of the myocardium is also called isovolumic pressure $\mathrm{P}_{\text {iso }}$ by physiologists, it is the pressure generated by the myocardium on the endocardium (inner surface of the myocardium) during a non-ejecting contraction of the myocardium. In this study we shall use the notation $\mathrm{P}_{\text {iso }}$ for the 
active pressure of the myocardium, and $\mathrm{P}_{\text {isom }}$ for its maximum value corresponding to the maximum state of activation of the cardiac muscle near end-systole.

In the following it is shown that the ejection fraction (EF) is simply one of several parameters that can be derived from the ESPVR to assess the performance of the left ventricle. Moreover the stroke volume (SV), and consequently the EF, can be directly related to the parameters describing the ESPVR, like slopes of the curve, areas under ESPVR having units of energy, pressures acting on the myocardium (ordinates of the curve), or ventricular volume changes (abscissas of the curve). This fact offers the possibility of a new understanding of the problem of heart failure with normal or preserved ejection fraction (HFpEF) in terms of the parameters describing the ESPVR introduced in this study.

\section{Mathematical model}

\subsection{Non-linear ESPVR}

As in previous publications [1-4], the left ventricle is represented as a thickwalled cylinder contracting symmetrically (see fig. 1). A helical myocardial fibre is projected on the cross-section as a dotted circle as in fig. 1, it will generate a

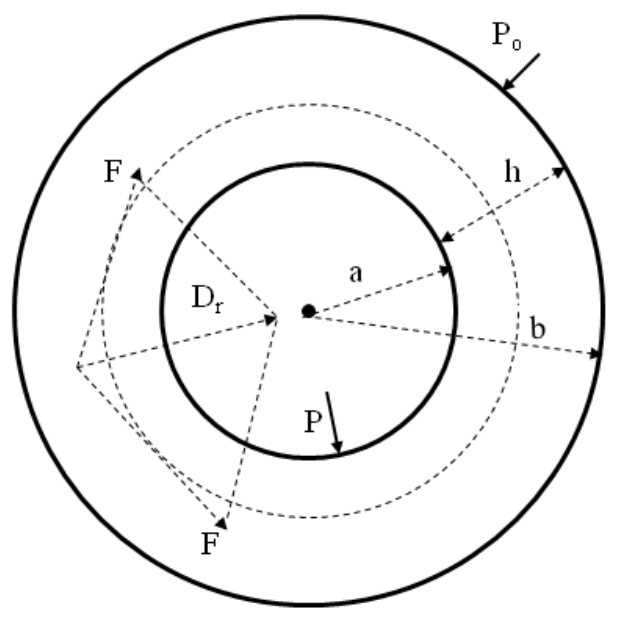

Figure 1: Cross-section of a thick-walled cylinder representing the left ventricle. A helical muscular fibre in the myocardium is projected on the cross-section as a dotted circle; a radial active force $\mathrm{D}_{\mathrm{r}}(\mathrm{r})$ (force/unit volume of the myocardium) is generated by the muscular fibre. Ventricular pressure $=\mathrm{P}$, outer pressure $=\mathrm{P}_{\mathrm{o}}$ (neglected in the calculation), inner radius $=a$, outer radius $=b$, thickness of the myocardium $\mathrm{h}=\mathrm{b}-\mathrm{a}$. 
radial active force $\mathrm{D}_{\mathrm{r}}(\mathrm{r})$ per unit volume of the myocardium and consequently an active pressure on the endocardium given by

$$
\int_{a}^{b} D_{r}(r) d r=\bar{D} h
$$

where $\overline{\mathrm{D}}$ is an average value obtained by applying the mean value theorem, $\mathrm{h}=$ $\mathrm{b}-\mathrm{a}=$ thickness of the myocardium, $\mathrm{a}=$ inner radius, $\mathrm{b}=$ outer radius of the myocardium. We shall use the notation $\mathrm{P}_{\text {iso }}=\overline{\mathrm{D} h}$ as indicated in the introduction, $\mathrm{P}_{\text {iso }}$ reaches its maximum $\mathrm{P}_{\text {isom }}$ (peak isovolumic pressure) near endsystole when the cardiac muscle reaches its maximum state of activation. In a quasi-static approximation (viscous and inertia forces neglected) the equilibrium of forces on the endocardium when the cardiac muscle reaches its maximum state of activation is given by (see fig. 1)

$$
P_{\text {isom }}-P_{m}=E_{2 m}\left(V_{e d}-V_{m}\right)
$$

where $\mathrm{P}_{\mathrm{m}}$ is the corresponding value of the left ventricular pressure $\mathrm{P}, \mathrm{V}_{\mathrm{m}}$ the corresponding value of the left ventricular volume $\mathrm{V}$ (We have $\mathrm{V}_{\mathrm{m}} \approx \mathrm{V}_{\mathrm{es}}$ the endsystolic volume when $\mathrm{dV} / \mathrm{dt}=0$ ), the elasticity coefficient $E_{2 \mathrm{~m}}=\tan \beta_{2}$ is the slope shown of the line $\mathrm{CD}$ in fig. 2. The right-hand side is the pressure generated on the endocardium due to the change of volume from $V_{\text {ed }}$ to $V_{m}$. The outer pressure $P_{o}$ in fig. 1 is neglected.

In fig. 2 the point $\mathrm{D}$ of coordinates $\left(\mathrm{P}_{\mathrm{m}}, \mathrm{V}_{\mathrm{m}}\right)$ will describe the ESPVR represented by the curve BDC as if a balloon is inflated against a constant $\mathrm{P}_{\text {isom }}$. Equation (2) can be split into two equations as follows:

$$
\begin{gathered}
P_{m}=E_{1 m}\left(V_{m}-V_{o m}\right) \\
P_{\text {isom }}=E_{m}\left(V_{\text {ed }}-V_{\text {om }}\right)
\end{gathered}
$$

As shown in fig. 2, $\mathrm{V}_{\text {om }}$ is the intercept of the ESPVR with the volume axis. We have also the notation $E_{1 \mathrm{~m}}=\tan \beta_{1}$ (slope of the line DB) and $E_{m}=\tan \alpha$ (slope of the line CB). Equations (2) and (3) are two different ways to express the relation between $P_{m}$ and $V_{m}$ on the ESPVR represented by the curve BDC, the mathematical expressions of this curve and slope coefficients are given in [57]. The slopes $E_{2 m}=\tan \beta_{2}, E_{1 m}=\tan \beta_{1}$ and $E_{m}=\tan \alpha$ correspond to the maximum elastance $\mathrm{E}_{\max }$ in the linear model of ESPVR [8-11]. The following slopes of the ESPVR are also used in this study (see fig. 2):

$$
\tan \gamma=\frac{d P_{m}}{d V_{m}}=\frac{P_{t}-P_{m}}{S V}=\frac{P_{m}}{V_{m}-V_{o t}}=\frac{P_{t}}{V_{e d}-V_{o t}}
$$

is the tangent to the ESPVR at point $\mathrm{D}$ with coordinates $\left(\mathrm{P}_{\mathrm{m}}, \mathrm{V}_{\mathrm{m}}\right), \mathrm{V}_{\text {ot }}$ is the intercept of the tangent with the volume axis and $P_{t}$ is the ordinate of the intercept of the tangent with the vertical line AC.

$$
\begin{gathered}
\tan \gamma_{1}=\text { tangent to the ESPVR at point } \mathrm{B}\left(0, \mathrm{~V}_{\mathrm{om}}\right) \\
\tan \gamma_{3}=\text { tangent to the ESPVR at point } \mathrm{C}\left(\mathrm{P}_{\mathrm{isom}}, \mathrm{V}_{\mathrm{ed}}\right) \\
\tan \beta_{2}=\frac{P_{\text {isom }}-P_{m}}{S V}=\frac{P_{\text {isom }}}{V_{e d}-V_{o 2}}=\frac{P_{m}}{V_{m}-V_{o 2}}
\end{gathered}
$$

where $\mathrm{V}_{\mathrm{o} 2}$ is the intercept of the line $\mathrm{CD}$ in fig. 2 with the volume axis. 
136 Modelling in Medicine and Biology X

$$
\tan \beta_{1}=\frac{P_{s}-P_{m}}{S V}=\frac{P_{S}}{V_{e d}-V_{o m}}=\frac{P_{m}}{V_{m}-V_{o m}}
$$

where $\mathrm{P}_{\mathrm{s}}$ is the ordinate of the intercept of the line BD the vertical axis AC.

$$
\begin{gathered}
\tan \alpha=\frac{P_{\text {isom }}}{V_{e d}-V_{o m}}=\text { slope of the line } \mathrm{P}_{\text {isom }} \mathrm{V}_{\text {om }} \text { (line BC) } \\
e_{a m}=\frac{P_{m}}{S V}=\text { arterial elastance near end-systole }
\end{gathered}
$$

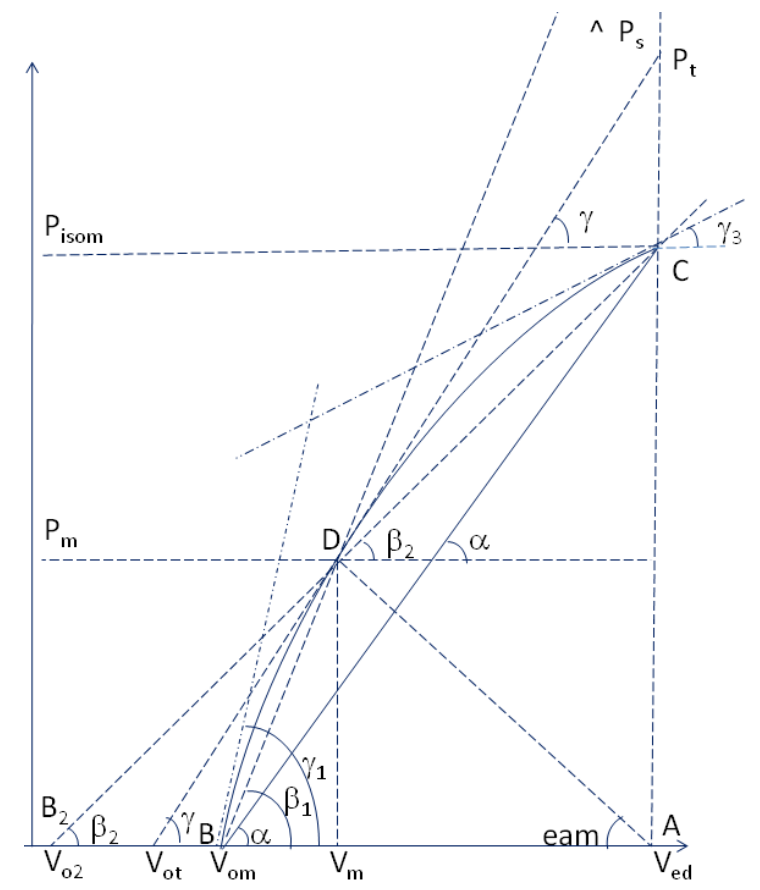

Figure 2: $\quad$ Non-linear ESPVR represented by the curve BDC, the point $\mathrm{D}$ on the ESPVR has coordinates $\left(\mathrm{P}_{\mathrm{m}}, \mathrm{V}_{\mathrm{m}}\right) . \mathrm{E}_{\mathrm{m}}=\tan \alpha$ slope of the line $\mathrm{BC}, \mathrm{E}_{2 \mathrm{~m}}=\tan \beta_{2}$ slope of the line $\mathrm{B}_{2} \mathrm{C}, \mathrm{E}_{1 \mathrm{~m}}=\tan \beta_{1}$ slope of the line $\mathrm{BD}$ (the intersection of which with the vertical line $\mathrm{AC}$ is the point with ordinate $\mathrm{P}_{\mathrm{s}}$ ), $\tan \gamma_{1}$ is the slope of the tangent at point $\mathrm{B}$ to the curve $\mathrm{BDC}, \tan \gamma_{3}$ is the slope of the tangent at point $\mathrm{C}$ to the curve $\mathrm{BDC}, \tan \gamma$ is the slope of the tangent at point $\mathrm{D}$ to the curve BDC (the intersection of which with the vertical line $\mathrm{AC}$ is the point with ordinate $\mathrm{P}_{\mathrm{t}}$ ), $\mathrm{e}_{\mathrm{am}}$ is the slope of the line DA and corresponds to the arterial elastance.

From the previous relations one can easily derive the following ratios

$$
\frac{\tan \gamma}{e_{a m}}=\frac{S V}{V_{m}-V_{o t}} \quad \frac{\tan \beta_{2}}{e_{a m}}=\frac{S V}{V_{m}-V_{o 2}} \quad \frac{\tan \beta_{1}}{e_{a m}}=\frac{S V}{V_{m}-V_{o m}}
$$


Equations (12) give an idea of the many relations that exit between the stroke volume SV (and consequently ejection fraction $\mathrm{EF}=\mathrm{SV} / \mathrm{V}_{\mathrm{ed}}$ ) and the parameters describing the ESPVR. It shows that the EF can be studied by a careful study of the parameters describing the ESPVR, which can bring a new insight in the problem of HFpEF. It is evident that the parameters describing the ESPVR reflect in some way the state of the myocardium.

\subsection{Areas under the ESPVR}

When the point $\mathrm{D}$ with coordinates $\left(\mathrm{P}_{\mathrm{m}}, \mathrm{V}_{\mathrm{m}}\right)$ moves along the ESPVR (see fig. 2), the stroke work $\mathrm{SW} \approx \mathrm{P}_{\mathrm{m}}\left(\mathrm{V}_{\mathrm{ed}}-\mathrm{V}_{\mathrm{m}}\right)$ is maximum under the following condition:

$$
\frac{d(S W)}{d V_{m}} \approx \frac{d}{d V_{m}}\left[P_{m}\left(V_{e d}-V_{m}\right)\right]=\left(V_{e d}-V_{m}\right) \frac{d P_{m}}{d V_{m}}-P_{m}=0
$$

which by using eqns (5) and (11) gives

$$
\tan \gamma_{x}=e_{a m x}
$$

corresponding to $\mathrm{SW}=\mathrm{SW}_{\mathrm{x}}$ (maximum stroke work), $\mathrm{P}_{\mathrm{m}}=\mathrm{P}_{\mathrm{mx}}$ and $\mathrm{V}_{\mathrm{m}}=\mathrm{V}_{\mathrm{mx}}$. The stroke work reserve SWR [3] is an expression of the difference between the stroke work SW and its maximum value $\mathrm{SW}_{\mathrm{x}}$. We have

$$
S W R=S W_{x}-S W \approx P_{m x}\left(V_{e d}-V_{m x}\right)-P_{m}\left(V_{e d}-V_{m}\right)
$$

SWR measures the ability of the heart to increase its output under increase of load demand as reflected by an increase in $\mathrm{P}_{\mathrm{m}}$, it gives an interesting index for the evaluation of the ventricular performance. One can distinguish the following conditions:

a) $\tan \gamma<\mathrm{e}_{\mathrm{am}}$, with $\mathrm{P}_{\mathrm{m}}<\mathrm{P}_{\mathrm{mx}}, \mathrm{V}_{\mathrm{m}}<\mathrm{V}_{\mathrm{mx}}$ and $\mathrm{SW}<\mathrm{SW}_{\mathrm{x}}$. It corresponds to a normal state of the heart. An increase of $\mathrm{P}_{\mathrm{m}}$ due to increase in load demand results in a corresponding increase in SW.

b) $\tan \gamma_{\mathrm{x}}=\mathrm{e}_{\mathrm{amx}}$, with $\mathrm{P}_{\mathrm{m}}=\mathrm{P}_{\mathrm{mx}}, \mathrm{V}_{\mathrm{m}}=\mathrm{V}_{\mathrm{mx}}$ and $\mathrm{SW}=\mathrm{SW}_{\mathrm{x}}$. It corresponds to a mildly depressed state of the heart. An increase in $\mathrm{P}_{\mathrm{m}}$ due to increase in load demand results in a decrease of SW.

c) $\tan \gamma>\mathrm{e}_{\mathrm{am}}$, with $\mathrm{P}_{\mathrm{m}}>\mathrm{P}_{\mathrm{mx}}, \mathrm{V}_{\mathrm{m}}>\mathrm{V}_{\mathrm{mx}}$ and $\mathrm{SW}<\mathrm{SW}_{\mathrm{x}}$. It corresponds to a severely depressed state of the heart. An increase of $P_{m}$ due to increase in load demand results in a severe decrease in SW causing cardiac insufficiency and heart failure.

\section{Application to medical data}

The medical data are taken from the work of Azancot et al. [12] and are reproduced in Table 1 of this study. There are four clinical groups shown in Table 1, normal group, hypertension, dilated myocardium and volume overload. The values of $\mathrm{V}_{\mathrm{om}}, \mathrm{V}_{\mathrm{ot}}, \mathrm{V}_{\mathrm{o} 2}$ and $\mathrm{P}_{\mathrm{isom}}$ in Table 1 for the four clinical groups have been calculated by using the exact expressions of the slopes using the procedure indicated in [5] (in other words we did not use the approximation $\log (1+\mathrm{x}) \approx \mathrm{x}$ 
as discussed in [5]). The left ventricular pressure $\mathrm{P}_{\mathrm{m}}$ near end-systole has been approximated by the mean arterial pressure map given in [12]. We have verified that slight variation of $\mathrm{P}_{\mathrm{m}}$ around map does not affect the results obtained.

Figure 3 shows the relations of $V_{\text {ot }}$ with $V_{\text {om }}$ and $V_{o 2}$ with $V_{\text {om }}$, it confirms what is known from the study of linear ESPVR [8-11] that the values of $V_{\text {om }}$ (and $\mathrm{V}_{\mathrm{ot}}, \mathrm{V}_{\mathrm{o} 2}$ ) tend to be smaller for the normal state of the left ventricle and to increase in case of cardiomyopathies with a shift of the ESPVR to the right. Notice the overlap between normal cases (*) and cases of hypertrophy (x). A linear least square fit between $\mathrm{V}_{\mathrm{ot}}$ and $\mathrm{V}_{\mathrm{om}}$ gives $\mathrm{V}_{\mathrm{ot}}=0.792 \mathrm{~V}_{\mathrm{om}}-0.886$ with correlation coefficient $r=0.99$. Figure 4 shows relations between $\tan \gamma$ and $\tan \alpha$ that confirm again what is known from the study of linear ESPVR, that the value of the slope of the ESPVR tends to be higher in the normal state of the left ventricle and lower in cases of cardiomyopathies. Again we notice the overlap between normal cases $(*)$ and some cases of hypertrophy $(\mathrm{x})$ in fig. 4.
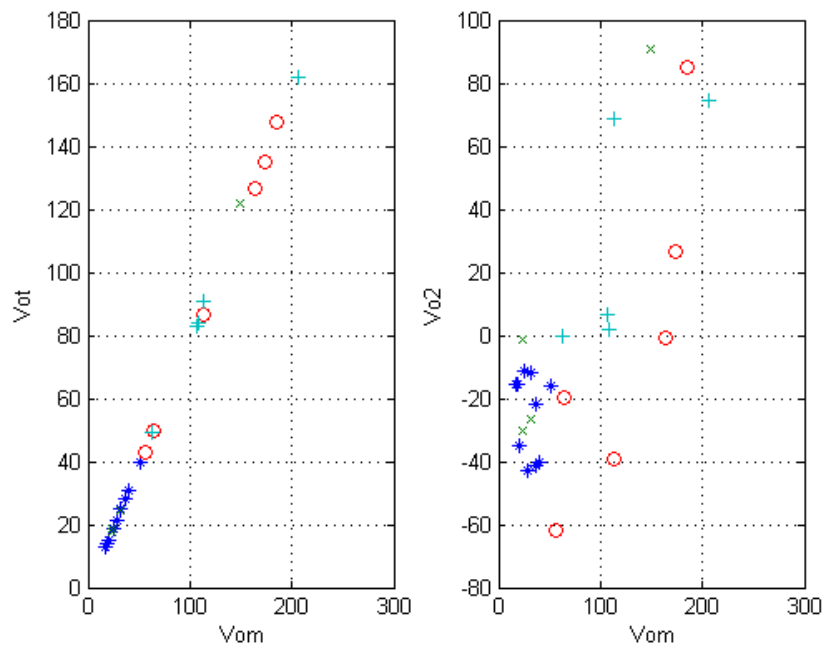

Figure 3: Relations between the volume intercepts $\mathrm{V}_{\text {om }}, \mathrm{V}_{\text {ot }}$ and $\mathrm{V}_{\mathrm{o} 2}$ shown in fig. 2 and reported in Table 1 . Notice that the values of $\mathrm{V}_{\mathrm{ot}}$ and $\mathrm{V}_{\mathrm{om}}$ tend to be smaller for the normal group; normal group *, hypertension $\mathrm{x}$, volume overload o, dilated $\mathrm{MC}+$.

The quantity $\left(\mathrm{V}_{\mathrm{mx}}-\mathrm{V}_{\mathrm{m}}\right) /\left(\mathrm{V}_{\mathrm{ed}}-\mathrm{V}_{\mathrm{m}}\right)$ measures the relative deviation of $\mathrm{V}_{\mathrm{m}}$ from $V_{\mathrm{mx}}$, the ventricular volume corresponding to the case where the stroke work SW is maximum and equal to $\mathrm{SW}_{\mathrm{x}}$. When $\left(\mathrm{P}_{\mathrm{m}}, \mathrm{V}_{\mathrm{m}}\right)$ moves along the ESPVR, the case $V_{m x}-V_{m}<0$ corresponds to a severely depressed state of the heart as discussed in the previous paragraph. The stroke work reserve SWR = $\mathrm{SW}_{\mathrm{x}}$ - SW can be used also to identify normal from abnormal state of the myocardium. These two quantities are shown in fig 5 with the ejection fraction EF as abscissa. In fig. 6 are graphical relations derived from eqns (12). One can notice the trend in figs 5 and 6 that indicates that cases of cardiomyopathies 
correspond to small EF and small values of the volumes ratios indicated. From figs 5 and 6 when $\mathrm{SWR}=0$ (or $\mathrm{V}_{\mathrm{m}}=\mathrm{V}_{\mathrm{mx}}$ ) we observe the ratios

$$
\begin{gathered}
S V / V_{e d} \approx 0.3 \\
\left(P_{\text {isom }}-P_{m}\right) / P_{\text {isom }}=S V /\left(V_{e d}-V_{o 2}\right) \approx 0.4 \\
\left(P_{t}-P_{m}\right) / P_{t}=S V /\left(V_{e d}-V_{o t}\right) \approx 0.5 \\
\left(P_{s}-P_{m}\right) / P_{s}=S V /\left(V_{e d}-V_{o m}\right) \approx 0.6
\end{gathered}
$$

\begin{tabular}{|c|c|c|c|c|c|c|c|c|c|c|}
\hline $\begin{array}{l}\mathrm{V}_{\text {ed }} \\
\mathrm{ml}\end{array}$ & $\mathrm{V}_{\mathrm{\omega}} / \mathrm{V}_{\mathrm{ed}}$ & $\begin{array}{l}V_{\text {es }} \\
\mathrm{ml}\end{array}$ & $\begin{array}{c}\text { map } \\
\text { mmHg }\end{array}$ & $\begin{array}{c}\mathrm{P}_{\text {isom }} \\
\mathrm{mmHg}\end{array}$ & $\begin{array}{c}\mathrm{P}_{\mathrm{t}} \\
\mathrm{mmHg}\end{array}$ & $\tan \gamma / \mathrm{e}_{\mathrm{am}}$ & $\tan \alpha / \mathrm{e}_{\mathrm{am}}$ & $\begin{array}{l}\mathrm{V}_{\text {om }} \\
\mathrm{ml}\end{array}$ & $\begin{array}{l}V_{\text {ot }} \\
\mathrm{ml}\end{array}$ & $\begin{array}{l}\mathrm{V}_{\mathrm{o} 2} \\
\mathrm{ml}\end{array}$ \\
\hline \multicolumn{11}{|c|}{ Normal group } \\
\hline 171 & 1.03 & 42.75 & 109 & 272.3 & 768.3 & 6.05 & 2.25 & 28.5 & 21.6 & -42.9 \\
\hline 190 & 0.91 & 55.10 & 93 & 223.2 & 556.4 & 4.98 & 2.11 & 36.9 & 28.0 & -41.2 \\
\hline 211 & 1.47 & 61.19 & 100 & 247.3 & 596.5 & 4.97 & 2.18 & 40.8 & 31.0 & -40.5 \\
\hline 90 & 1.37 & 27.90 & 84 & 203.6 & 465.0 & 4.54 & 2.11 & 18.6 & 14.2 & -15.7 \\
\hline 130 & 2.19 & 48.10 & 130 & 307.0 & 586.3 & 3.51 & 1.98 & 32.1 & 24.8 & -12.1 \\
\hline 185 & 0.95 & 75.85 & 110 & 240.5 & 440.6 & 3.01 & 1.79 & 51.4 & 39.5 & -16.2 \\
\hline 83 & 1.31 & 24.90 & 127 & 309.5 & 729.7 & 4.75 & 2.13 & 16.6 & 12.7 & -15.5 \\
\hline 157 & 1.24 & 54.95 & 80 & 186.6 & 385.6 & 3.82 & 1.98 & 36.9 & 28.2 & -21.6 \\
\hline 138 & 1.79 & 30.36 & 97 & 256.2 & 783.5 & 7.10 & 2.41 & 20.1 & 15.2 & -35.2 \\
\hline 99 & 1.27 & 36.63 & 75 & 172.3 & 338.8 & 3.52 & 1.93 & 24.6 & 18.9 & -11.4 \\
\hline \multicolumn{11}{|c|}{ Dilated MC } \\
\hline 313 & 1.22 & 156.5 & 78 & 159.5 & 243.7 & 2.12 & 1.55 & 106.3 & 82.9 & 6.7 \\
\hline 190 & 0.96 & 93.10 & 80 & 163.2 & 256.6 & 2.21 & 1.56 & 63.5 & 49.2 & -0.2 \\
\hline 318 & 0.88 & 159.0 & 80 & 161.0 & 250.1 & 2.13 & 1.53 & 108.7 & 84.2 & 2.0 \\
\hline 206 & 0.91 & 160.7 & 73 & 109.0 & 120.4 & 0.67 & 0.73 & 113.1 & 90.9 & 68.7 \\
\hline 463 & 0.77 & 296.3 & 102 & 178.7 & 228.2 & 1.24 & 1.14 & 205.9 & 161.6 & 74.7 \\
\hline \multicolumn{11}{|c|}{ Hypertrophic MC } \\
\hline 160 & 2.20 & 48.00 & 116 & 290.7 & 665.6 & 4.74 & 2.19 & 32.9 & 24.4 & -26.4 \\
\hline 288 & 1.96 & 216. & 92 & 145.0 & 162.3 & 0.76 & 0.82 & 149.8 & 121.8 & 91.0 \\
\hline 145 & 3.95 & 34.80 & 90 & 241.9 & 661.3 & 6.35 & 2.43 & 23.0 & 17.4 & -30.5 \\
\hline 83 & 3.72 & 35.69 & 104 & 237.2 & 391.9 & 2.77 & 1.82 & 23.8 & 18.6 & -1.26 \\
\hline \multicolumn{11}{|c|}{ Volume overload } \\
\hline 468 & 0.60 & 238.7 & 81 & 158.6 & 246.9 & 2.05 & 1.48 & 164.5 & 126.7 & -0.57 \\
\hline 400 & 1.26 & 268.0 & 83 & 142.9 & 173.9 & 1.10 & 1.06 & 185.3 & 147.5 & 85.1 \\
\hline 290 & 0.98 & 84.10 & 85 & 205.1 & 508.4 & 4.98 & 2.13 & 56.3 & 42.8 & -61.6 \\
\hline 396 & 0.65 & 166.3 & $81^{*}$ & 171.6 & 315.1 & 2.89 & 1.72 & 113.5 & 86.8 & -39.1 \\
\hline 469 & 1.00 & 253.3 & $85^{*}$ & 165.9 & 240.4 & 1.83 & 1.42 & 173.4 & 135.2 & 26.7 \\
\hline 239 & 1.29 & 95.60 & $83^{*}$ & 188.0 & 341.6 & 3.12 & 1.84 & 64.3 & 49.6 & -20.0 \\
\hline
\end{tabular}

Table 1: Calculation of $\mathrm{P}_{\text {isom }}, \mathrm{P}_{\text {isot }}, \mathrm{V}_{\mathrm{om}}, \mathrm{V}_{\mathrm{ot}}, \mathrm{V}_{\mathrm{o} 2}, \tan \gamma / \mathrm{e}_{\mathrm{am}}$ and $\tan \alpha / \mathrm{e}_{\mathrm{am}}$ for four clinical groups.

$\mathrm{V}_{\text {ed }}=$ end-diastolic volume, $\mathrm{V}_{\mathrm{es}}=$ end-systolic volume, $\mathrm{V}_{\omega}=$ volume of myocardium, map = mean arterial pressure (assumed $\approx \mathrm{P}_{\mathrm{m}}$ ), $\mathrm{P}_{\text {isom }}=$ peak isovolumic pressure based on non-linear model, $\mathrm{P}_{\mathrm{t}}=$ defined in eqn. (5), $\mathrm{V}_{\mathrm{om}}=$ intercept of the non-linear ESPVR with the volume axis, $\tan \gamma / \mathrm{e}_{\mathrm{am}}$ and $\tan \alpha / \mathrm{e}_{\mathrm{am}}$ as defined in text. Experimental values of $\mathrm{V}_{\mathrm{ed}}, \mathrm{V}_{\mathrm{es}}, \mathrm{V}_{\mathrm{\omega}} / \mathrm{V}_{\mathrm{ed}}$ and map taken from Azancot et al. [12]. 
experimentally in [8-10] by using a linear model for the ESPVR. This ratio tends to be relatively smaller in cases of cardiomyopathies with evident exceptions and fluctuations as can be noticed from Table 1. Figure 5 shows that $\mathrm{V}_{\mathrm{m}}=\mathrm{V}_{\mathrm{mx}}$

One can notice from eqns (14) and (16c) that $\tan \gamma=\mathrm{e}_{\mathrm{am}}$ when $\mathrm{SV} /\left(\mathrm{V}_{\mathrm{ed}}-\mathrm{V}_{\mathrm{ot}}\right)$ $=0.5$ corresponding to $\mathrm{SW}=\mathrm{SW}_{\mathrm{x}}$, in which case the difference between the angles $\gamma$ and $\alpha$ is relatively small (see fig. 4). From Table 1 we see that the ratio $\tan \alpha / \mathrm{e}_{\mathrm{am}} \approx 2$ for the normal group, which corresponds to a result verified corresponds to $\mathrm{SV} / \mathrm{V}_{\text {ed }} \approx 0.3$ and $\mathrm{SWR}=\mathrm{SW}_{\mathrm{x}}-\mathrm{SW}=0$. The values of the different ratios in fig. 6 for $S V / V_{\text {ed }} \approx 0.3$ are indicated in eqns (16). From fig. 6 one can see how the value of the ejection fraction $\mathrm{SV} / \mathrm{V}_{\text {ed }}$ is directly linked to the values of $\mathrm{V}_{\mathrm{ot}}, \mathrm{V}_{\mathrm{o} 2}, \mathrm{~V}_{\mathrm{om}}$.

The results presented in figs 4 to 6 show that the overlap between some cardiomyopathies and the normal group is not completely eliminated, but fig. 7 shows that a discrimate representation of the data calculated for the four clinical groups presented in Table 1 is possible. In fig. 7 (right) one can see that by replacing the variables $\mathrm{y}=\left(\mathrm{V}_{\mathrm{m}}-\mathrm{V}_{\mathrm{o} 2}\right) / \mathrm{SV}$ and $\mathrm{x}=\mathrm{SV} /\left(\mathrm{V}_{\mathrm{m}}-\mathrm{V}_{\mathrm{ot}}\right)$ by $(\mathrm{y}+$ mean $(\mathrm{y})) / \operatorname{std}(\mathrm{y})$ and $(\mathrm{x}+$ mean $(\mathrm{x})) / \operatorname{std}(\mathrm{x})$ for each clinical group, one can obtain a better discriminate separation of the four clinical groups. Similar observation was done by using other parameters.
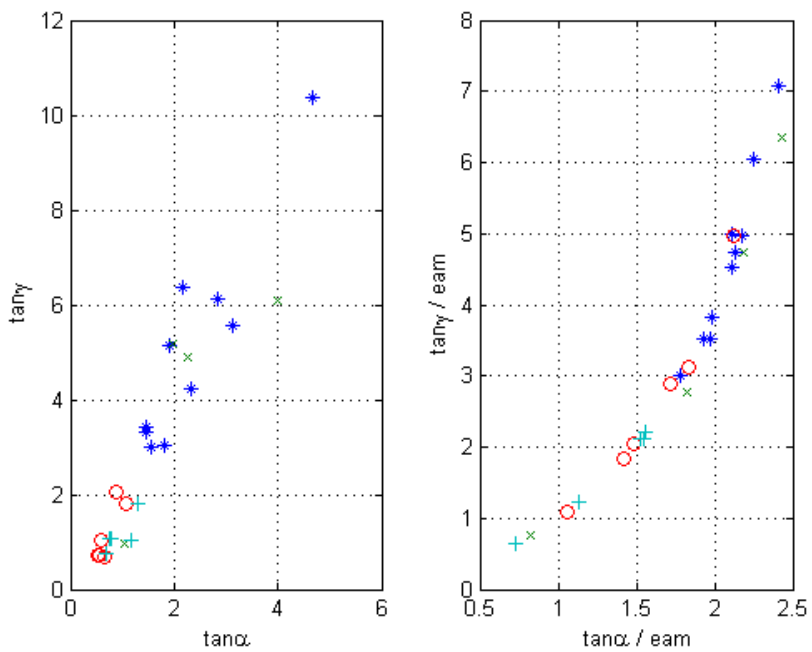

Figure 4: (left) Relation between the tangents $\tan \gamma$ and $\tan \alpha$; (right) Relation between $\tan \gamma / \mathrm{e}_{\mathrm{am}}$ and $\tan \alpha / \mathrm{e}_{\mathrm{am}}$ as calculated in Table 1. Notice that these values tend to be smaller in cases of cardiomyopathies; normal group *, hypertension x, volume overload o, dilated MC +. 

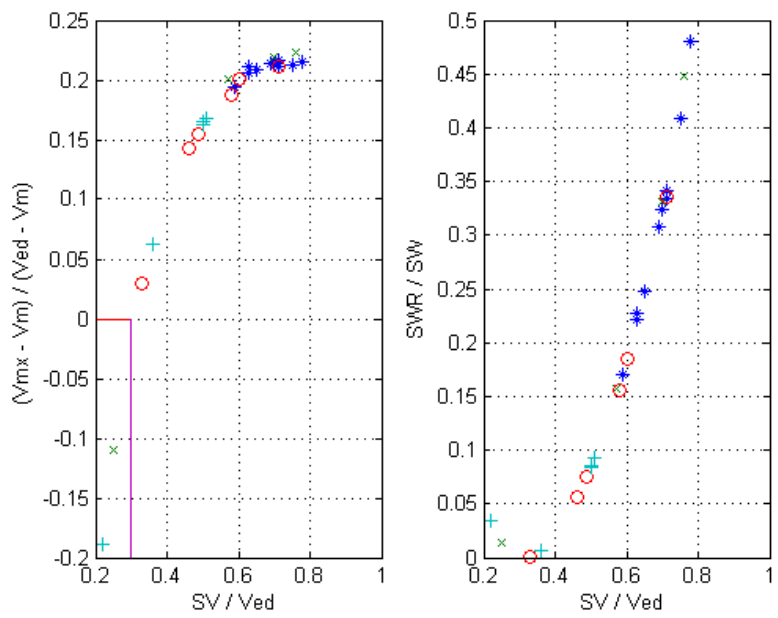

Figure 5: Values of $\mathrm{EF}=\mathrm{SV} / \mathrm{V}_{\text {ed }}$ tend to be generally smaller in cases of cardiomyopathies, with $\mathrm{SV} / \mathrm{V}_{\text {ed }} \approx 0.3$ for $\mathrm{V}_{\mathrm{mx}}-\mathrm{V}_{\mathrm{m}}=0$ and stroke work reserve SWR $=0$; normal group *, hypertrophy $\mathrm{x}$, volume overload o, dilated $\mathrm{MC}+$.
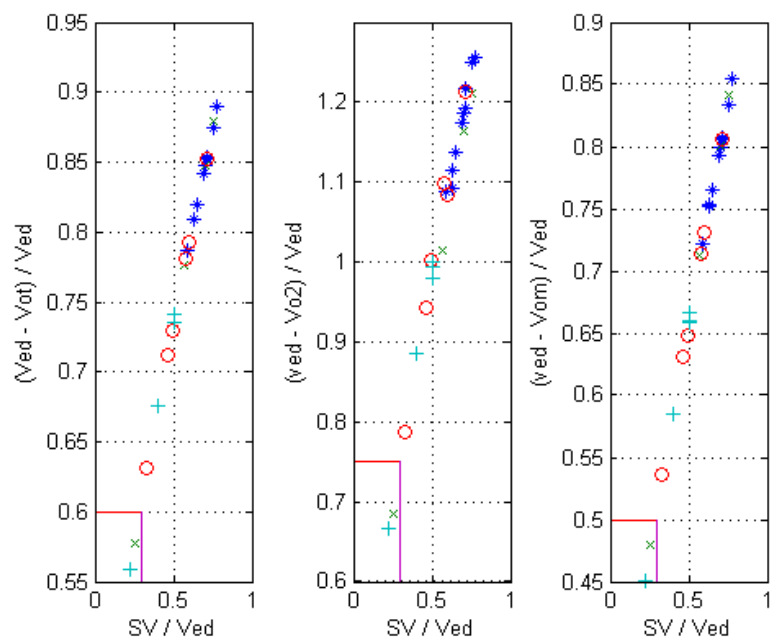

Figure 6: Relations that show how the ejection fraction is linked to the values of $\mathrm{V}_{\text {ot }}, \mathrm{V}_{\mathrm{o} 2}$ and $\mathrm{V}_{\text {om }}, \mathrm{SV} / \mathrm{V}_{\text {ed }} \approx 0.3$ corresponds to $\mathrm{SV} /\left(\mathrm{V}_{\text {ed }}-\mathrm{V}_{\text {ot }}\right) \approx$ $0.6, \mathrm{SV} /\left(\mathrm{V}_{\text {ed }}-\mathrm{V}_{\text {o2 }}\right) \approx 0.75, \mathrm{SV} /\left(\mathrm{V}_{\text {ed }}-\mathrm{V}_{\text {om }}\right) \approx 0.5$; normal group $*$, hypertrophy $\mathrm{x}$ volume overload o, dilated $\mathrm{MC}+$. 

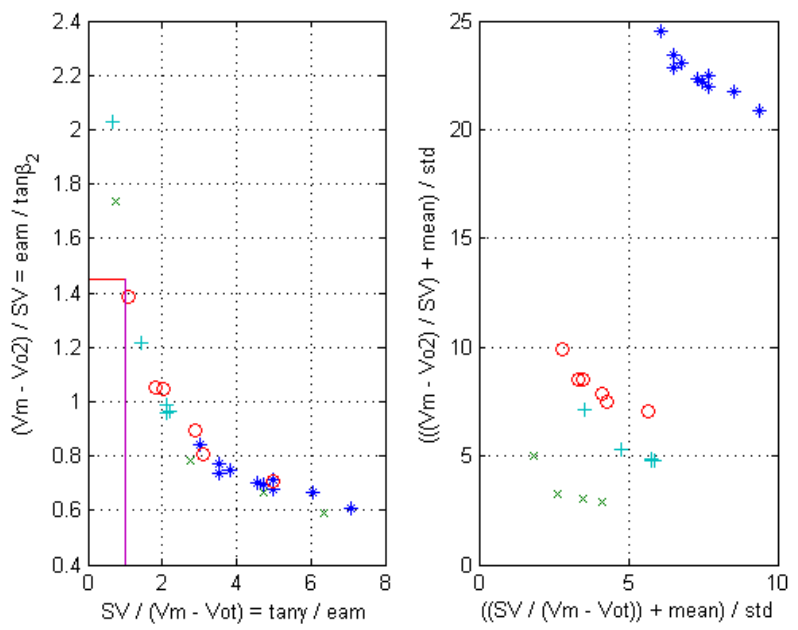

Figure 7: (left) Relation between $\mathrm{y}=\left(\mathrm{V}_{\mathrm{m}}-\mathrm{V}_{\mathrm{o} 2}\right) / \mathrm{SV}$ and $\mathrm{x}=\mathrm{SV} /\left(\mathrm{V}_{\mathrm{m}}-\mathrm{V}_{\mathrm{ot}}\right)$; (right) Relation between $(\mathrm{y}+\operatorname{mean}(\mathrm{y})) / \operatorname{std}(\mathrm{y})$ and $(\mathrm{x}+$ mean $(x)) / \operatorname{std}(x)$, notice how a discriminate grouping between the four clinical groupings is possible; normal group *, hypertrophy $\mathrm{x}$, volume overload o, dilated $\mathrm{MC}+$.

\section{Conclusion}

The study of cardiomyopathies with normal ejection fraction and the related problem of HFpEF has been the object of extensive studies in recent times. In this study we have derived some relations between the ejection fraction and some parameters describing the non-linear ESPVR that give some new insight in the way these parameters influence the ejection fraction. Evidently the ESPVR and its parameters reflect in some way the state of the myocardium. No one parameter derived in this study allows a full discriminate analysis between the four clinical groups presented. But the new parameters introduced opens the possibility of multivariate analysis that can lead to a better discriminate separation of the results calculated for different clinical groups.

\section{References}

[1] Shoucri, R.M., The pressure-volume relation and the mechanics of left ventricular contraction. Japanese Heart Journal, 31, pp. 713-729, 1990.

[2] Shoucri, R.M., Theoretical study of pressure-volume relation in left ventricle. Am. J. Phsiol. Heart Circ. Physiol., 260, pp. 282-H291, 1991.

[3] Shoucri, R.M., Possible clinical applications of the external work reserve. Jpn. Heart J., 35, pp. 771-787, 1994. 
[4] Shoucri, R.M., Mathematical aspects of the mechanics of left ventricular contraction. Int. J. of Design \& Nature and Ecodynamics, 5, pp. 1-16, 2010.

[5] Shoucri, R.M., Numerical evaluation of the slope and intercept of endsystolic pressure-volume relation. Environmental Health \& Biomedicine, (BIOMED 2011), eds. C.A. Brebbia, M. Eglite, I, Knets, R. Miftahof, V. Popov, WIT Press: Southampton and Boston, pp. 333-345, 2011.

[6] Shoucri, R.M., A method to calculate the parameters of non-linear ESPVR in the ventricles I. Proceedings of the World Medical Conference, eds. C. Rivas-Echeverria, K. Allegaert, D.E. Wainstein, Prague, Czech Republic, pp. 142-149, 2011.

[7] Shoucri, R.M., A method to calculate the parameters of isovolumic curves in the ventricles II. Proceedings of the World Medical Conference, eds. eds. C. Rivas-Echeverria, K. Allegaert, D.E. Wainstein, Prague, Czech Republic, pp. 150-155, 2011.

[8] Burkhoff, D., Sagawa, K., Ventricular efficiency predicted by an analytical model. Am. J. physiol., 250, pp. R1021-R1027, 1986.

[9] Asanoi, H., Sasayama, S., Kamegama, T., Ventriculo-arterial coupling in normal and failing heart in humans. Circ. Res., 65, pp. 91-98, 1989.

[10] Brimioulle, S., Waulthy, P., Ewalenko, P., Rondelet, B., Vermeulen, F., Kerbaul, F., Naeije, R., Single-beat estimation of right ventricular endsystolic pressure-volume relationship. Am. J. physiol. Heart Circ. Physiol., 284, pp. H1625-H1630, 2003.

[11] Burkhoff, D., Mirsky, I., Suga, H., Assessment of systolic and diastolic ventricular properties via pressure-volume analysis: a guide for clinical, translational, and basic researchers. Am. J. Physiol. Heart Circ. Physiol., 289, pp. H501-H512, 2005.

[12] Azancot, I., Masquet, C., Bourthoumieux, A., Georgiopoulos, G., Slama, R., Bouvrain, Y., Myocardial hypertrophy, rate of change of free wall thickness and directional components of ventricular power in man. J. Physiol. (Paris) 77, pp. 695-703, 1981. 